Table 1. Orbital energies (in hartree) of the $\mathrm{Ru}(\mathrm{bpy})_{2}(\mathrm{CN})_{2}$ complex in different media

\begin{tabular}{|c|c|c|c|c|c|c|c|c|c|c|}
\hline Medium & HOMO - 9 & HOMO - 8 & HOMO - 7 & HOMO - 6 & HOMO - 5 & HOMO - 4 & HOMO - 3 & HOMO - 2 & HOMO - 1 & HOMO - 0 \\
\hline $\mathrm{H}_{2} \mathrm{O}$ & -0.30420 & -0.30219 & -0.29961 & -0.29164 & -0.28854 & -0.26303 & -0.26183 & -0.20931 & -0.20640 & -0.20220 \\
\hline $\mathrm{MeOH}$ & -0.30369 & -0.30139 & -0.29885 & -0.29081 & -0.28741 & -0.26314 & -0.26196 & -0.20885 & -0.20593 & -0.20164 \\
\hline EtOH & -0.30338 & -0.30093 & -0.29840 & -0.29032 & -0.28676 & -0.26320 & -0.26202 & -0.20859 & -0.20567 & -0.20133 \\
\hline $\mathrm{MeNO}_{2}$ & -0.29811 & -0.29442 & -0.29163 & -0.28343 & -0.27762 & -0.26658 & -0.26542 & -0.20681 & -0.20396 & -0.19849 \\
\hline DMSO & -0.29827 & -0.29459 & -0.29181 & -0.28360 & -0.27784 & -0.26657 & -0.26541 & -0.20689 & -0.20404 & -0.19859 \\
\hline MeCN & -0.29807 & -0.29438 & -0.29159 & -0.28339 & -0.27757 & -0.26659 & -0.26543 & -0.20679 & -0.20394 & -0.19847 \\
\hline Acetone & -0.29733 & -0.29361 & -0.29082 & -0.28264 & -0.27664 & -0.26665 & -0.26549 & -0.20645 & -0.20360 & -0.19806 \\
\hline THF & -0.29437 & -0.29062 & -0.28780 & -0.27970 & -0.27303 & -0.26691 & -0.26572 & -0.20516 & -0.20229 & -0.19648 \\
\hline $\mathrm{CH}_{2} \mathrm{Cl}_{2}$ & -0.29508 & -0.29132 & -0.28851 & -0.28039 & -0.27387 & -0.26685 & -0.26567 & -0.20546 & -0.20259 & -0.19684 \\
\hline $\mathrm{CHCl}_{3}$ & -0.29185 & -0.28813 & -0.28524 & -0.27722 & -0.27010 & -0.26712 & -0.26584 & -0.20411 & -0.20123 & -0.19518 \\
\hline $\mathrm{CCl}_{4}$ & -0.28384 & -0.28045 & -0.27705 & -0.26932 & -0.26760 & -0.26696 & -0.26027 & -0.20093 & -0.19805 & -0.19123 \\
\hline Vac & -0.27044 & -0.27014 & -0.26731 & -0.26532 & -0.26139 & -0.25361 & -0.24325 & -0.19537 & -0.19261 & -0.18420 \\
\hline Medium & LUMO + 0 & LUMO + 1 & LUMO + 2 & LUMO + 3 & LUMO + 4 & LUMO + 5 & LUMO + 6 & LUMO + 7 & LUMO + 8 & LUMO + 9 \\
\hline $\mathrm{H}_{2} \mathrm{O}$ & -0.08441 & -0.08305 & -0.05532 & -0.04797 & -0.04501 & -0.04430 & 0.00031 & 0.00406 & 0.01797 & 0.02069 \\
\hline $\mathrm{MeOH}$ & -0.08449 & -0.08310 & -0.05548 & -0.04801 & -0.04519 & -0.04439 & 0.00019 & 0.00395 & 0.01854 & 0.02125 \\
\hline EtOH & -0.08454 & -0.08313 & -0.05555 & -0.04804 & -0.04527 & -0.04444 & 0.00014 & 0.00389 & 0.01887 & 0.02159 \\
\hline $\mathrm{MeNO}_{2}$ & -0.08742 & -0.08577 & -0.05890 & -0.05126 & -0.04838 & -0.04761 & -0.00305 & 0.00070 & 0.02003 & 0.02308 \\
\hline DMSO & -0.08740 & -0.08576 & -0.05888 & -0.05126 & -0.04835 & -0.04760 & -0.00303 & 0.00072 & 0.01993 & 0.02298 \\
\hline MeCN & -0.08742 & -0.08577 & -0.05891 & -0.05126 & -0.04839 & -0.04762 & -0.00306 & 0.00070 & 0.02005 & 0.02310 \\
\hline Acetone & -0.08748 & -0.08580 & -0.05902 & -0.05128 & -0.04851 & -0.04766 & -0.00313 & 0.00062 & 0.02046 & 0.02351 \\
\hline THF & -0.08770 & -0.08591 & -0.05947 & -0.05141 & -0.04894 & -0.04785 & -0.00344 & 0.00034 & 0.02198 & 0.02497 \\
\hline $\mathrm{CH}_{2} \mathrm{Cl}_{2}$ & -0.08765 & -0.08589 & -0.05936 & -0.05137 & -0.04885 & -0.04780 & -0.00337 & 0.00041 & 0.02163 & 0.02464 \\
\hline $\mathrm{CHCl}_{3}$ & -0.08789 & -0.08602 & -0.05985 & -0.05158 & -0.04925 & -0.04800 & -0.00370 & 0.00011 & 0.02313 & 0.02602 \\
\hline $\mathrm{CCl}_{4}$ & -0.08852 & -0.08637 & -0.06110 & -0.05246 & -0.04991 & -0.04847 & -0.00453 & -0.00066 & 0.02624 & 0.02845 \\
\hline Vac & -0.08981 & -0.08717 & -0.06351 & -0.05463 & -0.05088 & -0.04956 & -0.00622 & -0.00224 & 0.03036 & 0.03057 \\
\hline
\end{tabular}


By the request of the referee we present the charges and charge differences on the main units of $\mathrm{Ru}(\mathrm{bpy})_{2}(\mathrm{CN})_{2}$

Table 2. Mulliken Charges of the main units of the $\mathrm{Ru}(\mathrm{bpy})_{2}(\mathrm{CN})_{2}$ complex in different media

\section{Singlet state}

\begin{tabular}{|c|c|c|c|c|c|c|}
\hline \multirow[b]{2}{*}{ Medium } & \multirow[b]{2}{*}{$q_{R u}$} & \multirow[b]{2}{*}{$q_{C N}$} & \multirow[b]{2}{*}{$q_{\text {bpy }}$} & \multicolumn{3}{|c|}{$\Delta q$} \\
\hline & & & & bpy-CN & Ru-bpy & $\mathrm{Ru}-\mathrm{CN}$ \\
\hline $\mathrm{H}_{2} \mathrm{O}$ & 0.69 & -0.602 & 0.256 & 0.8580 & 0.4340 & 1.2920 \\
\hline МeOH & 0.691 & -0.598 & 0.253 & 0.8510 & 0.4380 & 1.2890 \\
\hline EtOH & 0.692 & -0.597 & 0.251 & 0.8480 & 0.4410 & 1.2890 \\
\hline $\mathrm{MeNO}_{2}$ & 0.698 & -0.564 & 0.215 & 0.7790 & 0.4830 & 1.2620 \\
\hline DMSO & 0.698 & -0.564 & 0.215 & 0.7790 & 0.4830 & 1.2620 \\
\hline $\mathrm{MeCN}$ & 0.698 & -0.564 & 0.214 & 0.7779 & 0.4838 & 1.2617 \\
\hline Acetone & 0.699 & -0.561 & 0.212 & 0.7730 & 0.4870 & 1.2600 \\
\hline THF & 0.702 & -0.553 & 0.202 & 0.7550 & 0.5000 & 1.2550 \\
\hline $\mathrm{CH}_{2} \mathrm{Cl}_{2}$ & 0.701 & -0.555 & 0.204 & 0.7590 & 0.4970 & 1.2560 \\
\hline $\mathrm{CHCl}_{3}$ & 0.705 & -0.546 & 0.193 & 0.7390 & 0.5120 & 1.2510 \\
\hline $\mathrm{CCl}_{4}$ & 0.713 & -0.523 & 0.167 & 0.6900 & 0.5460 & 1.2360 \\
\hline Vac & 0.727 & -0.482 & 0.118 & 0.6000 & 0.6090 & 1.2090 \\
\hline
\end{tabular}

\section{Triplet state}

\begin{tabular}{|c|c|c|c|c|c|c|}
\hline \multirow[b]{2}{*}{ Medium } & \multirow[b]{2}{*}{$\mathrm{q}_{\mathrm{Ru}}$} & \multirow[b]{2}{*}{$q_{C N}$} & \multirow[b]{2}{*}{$\mathbf{q}_{\mathrm{bpy}}$} & \multicolumn{3}{|c|}{$\Delta q$} \\
\hline & & & & bpy-CN & Ru-bpy & $\mathrm{Ru}-\mathrm{CN}$ \\
\hline $\mathrm{H}_{2} \mathrm{O}$ & 0.815 & -0.513 & 0.106 & 0.6190 & 0.7090 & 1.3280 \\
\hline $\mathrm{MeOH}$ & 0.815 & -0.511 & 0.104 & 0.6150 & 0.7110 & 1.3260 \\
\hline EtOH & 0.816 & -0.51 & 0.102 & 0.6120 & 0.7140 & 1.3260 \\
\hline $\mathrm{MeNO}_{2}$ & 0.819 & -0.484 & 0.074 & 0.5580 & 0.7450 & 1.3030 \\
\hline DMSO & 0.819 & -0.484 & 0.075 & 0.5590 & 0.7440 & 1.3030 \\
\hline $\mathrm{MeCN}$ & 0.819 & -0.484 & 0.074 & 0.5580 & 0.7450 & 1.3030 \\
\hline Acetone & 0.819 & -0.482 & 0.072 & 0.5540 & 0.7470 & 1.3010 \\
\hline THF & 0.821 & -0.475 & 0.064 & 0.5390 & 0.7570 & 1.2960 \\
\hline $\mathrm{CH}_{2} \mathrm{Cl}_{2}$ & 0.821 & -0.477 & 0.066 & 0.5430 & 0.7550 & 1.2980 \\
\hline $\mathrm{CHCl}_{3}$ & 0.823 & -0.47 & 0.058 & 0.5280 & 0.7650 & 1.2930 \\
\hline $\mathrm{CCl}_{4}$ & 0.828 & -0.452 & 0.039 & 0.4910 & 0.7890 & 1.2800 \\
\hline Vac & 0.835 & -0.42 & 0.003 & 0.4230 & 0.8320 & 1.2550 \\
\hline
\end{tabular}

